\title{
Estudo Prévio 17 - Editorial
}

\author{
João Caria Lopes \\ joaocarialopes@gmail.com \\ CEACT/UAL - Centro de Estudos de Arquitetura, Cidade e Território da Universidade Autónoma \\ de Lisboa \\ Filipa Ramalhete \\ framalhete@autonoma.pt \\ CEACT/UAL - Centro de Estudos de Arquitetura, Cidade e Território da Universidade Autónoma \\ de Lisboa e CICS.Nova - Centro Interdisciplinar de Ciências Sociais da Universidade Nova de \\ Lisboa.
}

Para citação: LOPES, João Caria; RAMALHETE, Filipa - Estudo Prévio 17 - Editorial. Estudo Prévio 17. Lisboa: CEACT/UAL - Centro de Estudos de Arquitetura, Cidade e Território da Universidade Autónoma de Lisboa, 2020. ISSN: 2182-4339 [Disponível em: www.estudoprevio.net]. DOI: https://doi.org/10.26619/2182-4339/17ED

Creative Commons, licence CC BY-4.0: https://creativecommons.org/licenses/by/4.0/

Nesta publicação do número DEZASSETE da revista EP - Estudo Prévio, inauguramos um novo site, que responde a aspirações que já tínhamos há algum temo: uma melhor organização do seu conteúdo, uma atualização da experiência de quem a lê e ouve e também reunir as condições que nos permitam aspirar a mais e melhores indexações internacionais. Neste número, tivemos a oportunidade de juntar artigos que fazem parte de investigações em progresso e que nos permitem conhecer, com publicações originais, o que cada autor melhor conhece e os caminhos que está a percorrer. Contribuímos, assim, para a descoberta de melhor informação e de novos detalhes da história.

Com o presente número, não deixamos também de dar continuidade ao projeto editorial, promovendo a partilha e reflexão sobre novo conhecimento, aprofundado pelos nossos contribuidores e convidados, através da palavra escrita, falada, e também de narrativas de imagens, cruzando investigações de diferentes localizações geográficas, profissionais e temáticas, em prol de uma maior abertura a novos territórios do conhecimento. É com esse objetivo que publicamos mais uma vez, para além dos habituais artigos e recensões, um ensaio visual e uma recensão de projeto.

2020 está, sem dúvida, a ser um ano de mudanças, e o futuro apresenta-se incerto. É, por isso, com redobrada satisfação e esperança que operamos estas mudanças, para que em 2021 possamos celebrar o 10 aniversário da revista com novos projetos. Até breve! 